\title{
Grammatical Processing without Semantics? An Event-related Brain Potential Study of Preschoolers using Jabberwocky Sentences
}

\author{
Juan Silva-Pereyra ${ }^{1,2}$, Barbara T. Conboy ${ }^{1}$, Lindsay Klarman ${ }^{1}$, \\ and Patricia K. Kuhl ${ }^{1}$
}

\begin{abstract}
Behavioral studies have demonstrated that children develop a nearly adult-like grammar between 36 and 42 months, but few studies have addressed how the child's brain processes semantic versus syntactic information. In previous research, Silva-Pereyra and colleagues showed that distinct event-related potentials (ERPs) are elicited by semantic and syntactic violations in sentences in children as young as 30, 36, and 48 months, following the patterns displayed by adults. In the current study, we examined ERPs to syntactic phrase structure violations in real and jabberwocky sentences in 36-month-old children. Jabberwocky sentences are sentences in which content (open-class) words are replaced by pseudowords while function (closed-class) words are retained. Results showed that
\end{abstract}

\section{INTRODUCTION}

One important and widely used psychophysiological approach for studying language processing is the recording of event-related brain potentials (ERPs). These are averages of cortical electrical activity time-locked to some external or internal event. ERP components are classified according to their polarity (i.e., positive or negative deflections in the waveform), the time of their onset-to-offset or peak amplitude in milliseconds, and their topographical distribution across the scalp. ERP studies have provided crucial information, with an exquisite time resolution, about language processing in infants and young children (for reviews, see Friederici, 2005; Mills, Conboy, \& Paton, 2005; Kuhl, 2004). ERPs are ideally suited for studying how different aspects of language processing systems are established in young children, and to what extent they resemble well-established systems in adults.

\section{Sentence Processing Studies of Adults}

Adult studies of sentence processing have indicated that different ERP components reflect the involvement of

\footnotetext{
${ }^{1}$ University of Washington, ${ }^{2}$ Universidad Nacional Autónoma de México, Mexico
}

syntactically anomalous real sentences elicited two positive ERP effects: left-distributed effects from 500 to $750 \mathrm{msec}$ and 1050 to $1300 \mathrm{msec}$, whereas syntactically anomalous jabberwocky sentences elicited two negative ERP effects: a left-distributed effect from 750 to $900 \mathrm{msec}$ and a later broadly distributed effect from 950 to $1150 \mathrm{msec}$. The results indicate that when preschoolers process real English sentences, ERPs resembling the positive effects previously reported for adults are noted, although at longer latencies and with broader scalp distributions. However, when preschoolers process jabberwocky sentences with altered lexical-semantic content, a negative-going ERP component similar to one typically associated with the extraction of meaning is noted.

populations of neurons underlying different aspects of processing. The ERP component most commonly associated with the processing of semantic information in sentences is the N400 component (Kutas \& Hillyard, 1980). This is a negative wave that occurs between 250 and $500 \mathrm{msec}$ after stimulus onset, peaks around $400 \mathrm{msec}$, and typically has a larger amplitude over right posterior sites (Kutas \& Van Petten, 1994). The amplitude of the N400 to a particular word is highly sensitive to the immediate context in which it occurs, whether the context is a single word, a sentence, or discourse (Kutas \& Federmeier, 2000). ERP studies of adults processing grammatical anomalies in sentences have displayed an early left anterior negativity (ELAN) or left anterior negativity (LAN), a more centrally distributed negativity, and a late parietally distributed positivity (called P600). ELAN is a negative wave occurring between 150 and $250 \mathrm{msec}$ that is sensitive to word category (phrase structure) violations, whereas LAN is a component peaking between 300 and 500 msec elicited by word category as well as morphosyntactic violations, such as violation of agreement (Gunter, Friederici, \& Schriefers, 2000). Both components are observed independently of semantic constraints (Friederici, Hahne, \& Mecklinger, 1996; Münte \& Heinze, 1994). ${ }^{1}$ The P600 is 
a positive wave with a long latency, beginning around $500 \mathrm{msec}$ and lasting several hundred milliseconds, that is largest over centro-parietal regions. The P600 has been found to occur with several types of morphosyntactic violations (Morris \& Holcomb, 2005; Friederici \& Kotz, 2003; Friederici, 2002; Hagoort, Brown, \& Osterhout, 1999; Osterhout, McLaughlin, \& Bersick, 1997). For example, in the anomalous sentence, "The cats won't EATING the fish," the word EATING elicits a larger P600 amplitude than the word EAT in "The cats won't EAT the fish" (Osterhout \& Holcomb, 1995). In addition, negativities in the $200-500$ msec range, but more centrally distributed than the E/LAN, have been observed in adults to sentences that are anomalous in inflectional morphology (e.g., Morris \& Holcomb, 2005; Coulson, King, \& Kutas, 1998; Münte \& Heinze, 1994; Friederici, Pfeifer, \& Hanhe, 1993; Kutas \& Hillyard, 1983).

\section{Models of Sentence Processing}

The timing, polarity, and distribution of ERP effects elicited by semantic and syntactic violations have been interpreted within both serial and interactive models of sentence processing. Serial models assume that distinct, dissociable mechanisms underlie the processing of syntactic and semantic information, and are activated at different points in processing (e.g., Frazier, 1987). The computation of an initial syntactic structure is believed to precede semantic binding operations because structural information is necessary as input for thematic role assignment. A structure is initially assigned by the syntactic module exclusively on the basis of syntactic principles, and this information is subsequently passed to the semantic module for evaluation. The semantic module can reject the initial structure, resulting in the subsequent assignment of an alternative structure, as in the case of temporarily ambiguous sentences (Frazier, 1987). Thus, these models assume that there are distinct syntactic and semantic processing mechanisms, and interactions between different types of information take place at a later stage in sentence processing (e.g., Friederici, 2002; Frazier, 1995, 1998).

One such serial model has been proposed to account for the time course of ELAN, LAN, and P600 effects, as well as results from previous behavioral studies. Friederici's (1995, 2002) three-phase neurolinguistic model of sentence comprehension includes an initial syntactic analysis based on word category information, followed by processing of lexically bound semantic and morphosyntactic information for achieving thematic role assignment, and finally, integration of the initial syntactic structure with the subsequent morphosyntactic and lexical-semantic information. According to this model, the ELAN or LAN component evoked by a syntactic violation reflects the initial syntactic analysis and detection of errors, and the P600 component evoked by a syntactic violation represents a "repair process," where- as a P600 elicited by ambiguity resolution (i.e., "The horse raced past the barn fell") represents a "reanalysis process" that occurs when the initial syntactic structure does not map onto the thematic structure (Friederici, Hahne, \& Saddy, 2002). The P600 has also been claimed to reflect the inability of the syntactic parser to assign the preferred structure to incoming words (Hagoort, Brown, \& Groothusen, 1993).

Alternative psycholinguistic models propose that sentence processing relies on the interaction between all relevant sources of information, at the pragmatic, semantic, phonological, morphological, and syntactic levels (e.g., Elman, Hare, \& McRae, 2005; MacDonald, Pearlmutter, \& Seidenberg, 1994; Bates \& MacWhinney, 1989; MarslenWilson \& Tyler, 1980). These interactive or constraintsatisfaction models reject the idea that purely structural information necessarily has temporal priority over semantic information. Instead, lexical-semantic and morphosyntactic cues are believed to be examined and weighed together throughout the course of sentence processing, leading to the best possible mapping between form and meaning. Importantly, such views emphasize the roles that the input frequency of particular sentence constructions and validity of certain linguistic cues play in constraining sentence interpretation, along with real-world knowledge. For example, on-line sentence processing studies of English-speaking adults (Ferreira, 2003; Bates, Devescovi, \& Wulfeck, 2001; Bates \& MacWhinney, 1989; MacWhinney \& Bates, 1989) have shown a preference for canonical subject-verb-object (SVO) sentence interpretations. In other languages with more flexible word order, adults tend to rely on other morphosyntactic cues such as subject-verb agreement and semantic cues such as animacy (Bates et al., 2001; MacWhinney \& Bates, 1989). The SVO word order is such a valid, reliable cue in English that, in some cases, it can lead to implausible sentence interpretations (Ferreira, 2003; MacWhinney, Bates, \& Kliegl, 1984). In a strong SVO language such as English, comprehenders may initially rely on a basic "NVN/agentpatient" heuristic strategy that assumes the subject of a sentence is the agent and the object is the patient, leading to a "shallow" form of initial processing that does not take other syntactic information into account, although given enough time, a more complete form of processing can be accomplished using syntactic algorithms (Ferreira, 2003). Sentences are processed more easily when they conform to canonical word order, that is, the word order and semantic cues converge to yield a single interpretation, rather than opposing interpretations. Other basic heuristics emphasizing semantic and/or plausibility information may also be used in sentence processing (Ferreira, 2003).

Interactive views of language have been supported by ERP studies that show immediate semantic analysis/ integration effects in sentence processing, challenging the notion that automatic syntactic processes always operate prior to semantic processes or in an encapsulated manner (see Kutas, Van Petten, \& Kluender, 2006). 
Moreover, when adults process certain types of anomalous sentences which can be construed as either semantically or syntactically anomalous, semantics appear to guide the initial syntactic analysis of sentences, rather than the other way around (Kim \& Osterhout, 2005). The interactive school of thought also considers that the components and effects noted to syntactic anomalies in sentences may reflect more general cognitive processes, rather than the operation of specific linguistic modules. For example, the P600 effect observed to grammatically anomalous sentences has been interpreted as part of a family of more general P300 (P3b) effects that reflect context updating processes and/or responses to low probability target events (see Kutas et al., 2006; Coulson et al., 1998). The LAN has also been interpreted as reflecting general working memory processes rather than specific morphosyntactic processing (for review, see Kutas et al., 2006). Numerous studies have revealed less than clearcut dissociations between semantic and syntactic processes indexed by the N400, E/LAN, and P600 components (Kutas et al., 2006).

\section{Sentence Processing in Children}

Modular/serial versus interactive activation accounts of sentence processing tend to align with opposing views on language development in children. Many modular approaches to language development emphasize separate mechanisms for rule-based versus associative learning (e.g., Ullman, 2004; Pinker \& Ullman, 2002; Pinker, 1994, 1999; Chomsky, 1981). According to the "continuity" hypothesis, grammatical processing mechanisms are innate, although they may not function in a completely adult-like manner during childhood due to cognitive limitations (see Clahsen \& Fesler, 2006). Experience with language serves to trigger innate linguistic knowledge and the processing system becomes adult-like with maturation of other cognitive mechanisms (Pinker, 1994, 1999). Thus, according to these views, syntactic parsing mechanisms are believed to be in place during early childhood, but operating in a less efficient manner.

In contrast, according to usage-based, emergentist accounts of language development, experience with language is the primary force shaping the development of basic cognitive processing mechanisms into specialized networks for distinct aspects of language processing (see MacWhinney, 1999; Elman et al., 1996). On this view, knowledge about syntactic constructions and morphosyntax emerges gradually with growth in the lexicon, applying first to specific lexical items and later becoming abstract through generalization to other items (Goldberg, Casenhiser, \& Sethuraman, 2004; Lieven, Behrens, Speares, \& Tomasello, 2003; Savage, Lieven, Theakston, \& Tomasello, 2003; Tomasello, 2000, 2003; Bates \& Goodman, 1999; Lieven, Pine, \& Baldwin, 1997). From this perspective, sentence interpretation strategies are influenced by previous learning as well as ease of processing factors (Reyes \& Hernández, 2006; Dick, Wulfeck, Krupa-Kwiatkowski, \& Bates, 2004; Thal \& Flores, 2001; Bates et al., 1984). For example, the SVO preference has been noted for children learning other languages with more variable word order such as French (Kail \& Charvillat, 1988), German (Lindner, 2003), Italian (Devescovi, D'Amico, Smith, Mimica, \& Bates, 1998), and Spanish (Reyes \& Hernández, 2006), despite the fact that this is not a preferred pattern for adult speakers of those languages and not a reliable cue to agent-patient relations. When processing sentences, children may rely more on local cues such as word order because they are computationally easier to process than distributed/ topological cues such as subject-verb agreement and other morphological cues (Dick et al., 2004; Thal \& Flores, 2001; Von Berger, Wulfeck, Bates, \& Fink, 1996; Kail \& Charvillat, 1988; Bates et al., 1984). Thus, as experience with language is gained, and as cognitive abilities increase, children become increasingly able to use a variety of cues for sentence processing and rely on those that are most valid for their language.

\section{ERP Sentence Processing Effects in Children}

One important question that can be addressed using the ERP technique is whether the neural activity linked to sentence processing in children is similar or different from that noted in adults with respect to the components elicited by grammatical and semantic incongruities. Few previous studies have used ERPs to investigate sentence processing in preschool-age children. Silva-Pereyra and colleagues provided ERP evidence of semantic and syntactic processing at 30 months (Silva-Pereyra, Klarman, Lin, \& Kuhl, 2005) and at 36-48 months (Silva-Pereyra, Rivera-Gaxiola, \& Kuhl, 2005). At all three ages, children displayed a positive effect for syntactically anomalous sentences and a negative effect for semantically anomalous sentences, similar to the patterns reported for adults (see Kutas et al., 2006) and older children (Hahne, Eckstein, \& Friederici, 2004). Harris (2001) conducted two studies of syntactic processing with preschool-age children. In the first, 32- to 38-month-old children displayed a bilateral positivity from 500 to $1500 \mathrm{msec}$ to phrase structure anomalies in which the direct object of the verb was placed in preverbal position, and a negative effect for semantically anomalous sentences. However, in that study, there were differences in the word class (open- or closed-class) of the word immediately preceding the target in the syntactically anomalous versus control sentences, possibly leading to unequal baselines in the two conditions. In the second study, a different group of 36- to 39-month-old children showed a bilateral negativity from 300 to $600 \mathrm{msec}$ to phrase structure anomalies in which a closed-class word was inserted before the final noun phrase (NP). The differences across these studies are likely due to the different sentence types and the way in which the stimuli were presented 
(segmented speech in the former study, natural continuous speech in the latter). Another recent study investigating the processing of phrase-structure violations in 32-month-olds demonstrated a left hemispheric negativity around 500 msec and a late P600 (Oberecker, Friedrich, \& Friederici, 2005). A more recent study has also shown a late P600, but no negative effect, in 24-month-olds (Oberecker \& Friederici, 2006). The left lateralization of the negative effect in these studies has led to the interpretation of this effect as a child precursor to the E/LAN observed in adults for phrase structure violations. Both components, the E/LAN and the P600, started later and persisted longer than those observed in adults.

\section{The "Jabberwocky" Sentence Processing Paradigm}

One approach for investigating the coordination of semantic and syntactic processes during sentence comprehension is to analyze the processing of sentences that are syntactically intact but have greatly reduced lexical-semantic information, that is, jabberwocky sentences (based on the famous poem of Lewis Carroll, 1872). These are sentences in which content (openclass) words are replaced by pseudowords, and function (closed-class) words and verb inflections are kept as morphological markers (e.g., My macle platched a flovie about my garily). Such sentences can, therefore, be used to test the extent to which listeners rely on primarily syntactic information to build up expectations about sentence structure and to examine the brain processes involved when violations of such expectations occur.

\section{Jabberwocky ERP Studies of Adults}

Syntactic violations of subject-verb agreement (Münte, Matzke, \& Johannes, 1997) and phrase structure (Hahne \& Jescheniak, 2001; Canseco-Gonzalez, 2000) have been investigated in ERP studies of adults using real sentences and their corresponding jabberwocky sentences. These previous studies yielded mixed findings. Both CansecoGonzalez (2000) and Münte et al. (1997) reported early negative effects but not a P600 effect. Münte and colleagues concluded that it was not clear whether the negative effects they observed, which were maximal at central electrode sites, could be classified as LAN effects. Canseco-Gonzalez also observed a negativity to ungrammatical pseudoword stimuli, but this effect had a broad rather than a left-lateralized distribution, and therefore could not necessarily be interpreted as an ELAN or LAN. According to Canseco-Gonzalez and Münte et al., the absence of $\mathrm{P} 600$ effects observed in their studies reflects the absence of repair or reanalysis processes; there is no reason to repair or reanalyze a sentence containing syntactic errors unless semantic information is also pres- ent. On the contrary, Hahne and Jescheniak (2001) observed both a LAN and a P600 effect for real and jabberwocky sentences in adults. They suggested that the LAN effect reflected an initial parsing stage during which phrase structure information was processed, whereas the $\mathrm{P} 600$ reflected a repair process in which syntactic information was evaluated later in sentence processing and not based upon the semantics of the sentence. Based on these contradictory findings across studies, Hahne and Jescheniak proposed an explanation that relies on the time at which the semantic and syntactic processes are reflected in the ERP. Specifically, when an early negativity reflecting a purely syntactic process is present, as in their study, a P600 will also be noted because the process underlying the negativity will prevent detailed lexical-semantic processing of the syntactically anomalous item, and the P600 analysis process will ensue. In contrast, when the early negativity is absent, the syntactic error will be processed slightly later and at the same time as the semantic error, and this will block a subsequent P600 effect. In other words, the negativity noted in the studies of CansecoGonzalez and Münte et al. may have been an N400 effect to the pseudowords combined with a LAN-like effect.

\section{Goals of the Present Study}

\section{The Jabberwocky ERP Paradigm with Children}

In our previous ERP grammatical processing studies of children (Silva-Pereyra, Klarman, et al., 2005; SilvaPereyra, Rivera-Gaxiola, et al., 2005), the syntactic anomalies were presented in real sentences that contained intact lexical-semantic information. Of interest is whether children this age would show similar syntactic processing effects under conditions of greatly reduced semantic content, like the adults studied by Hahne and Jescheniak (2001), or different effects in the jabberwocky condition, like the adults studied by CansecoGonzalez (2000) and Münte et al. (1997). One other study (Harris, 2001) has provided ERP evidence of syntactic processing in 36- to 39-month-old children using jabberwocky sentences. In that study, phrase structure violations in real sentences elicited a negative effect between 300 and 600 msec, which was larger over the left than the right hemisphere, but significant only for children with higher language skills as determined by the Clinical Evaluation of Language Function-Preschool (CELF-P; Wiig, Secord, \& Semel, 1992). In contrast, phrase structure violations in jabberwocky sentences elicited a bilateral negativity from 600 to $700 \mathrm{msec}$, which was largest at left anterior electrode sites but significant only for the higher language group.

In the present study, we investigated the brain activity of 36-month-old children as they processed syntactic violations in real sentences, with intact lexical-semantic information, and jabberwocky sentences, in which lexical- 
semantic information was greatly reduced. Given that many aspects of grammar are acquired by approximately 3 years of age (Hirsh-Pasek \& Golinkoff, 1996; Brown, 1973), we predicted that children's ERPs to grammatically anomalous versus correct sentences would reflect patterns of the brain activity associated with syntactic processes. We predicted that if the positive ERP effect previously observed to syntactic anomalies in preschoolers (Silva-Pereyra, Klarman, et al., 2005; SilvaPereyra, Rivera-Gaxiola, et al., 2005) is a specialized syntactic component that occurs regardless of lexicalsemantic information, then syntactic anomalies in jabberwocky sentences should elicit similar ERPs as those in real sentences, that is, a late positivity after the onset of the word that renders the sentence ungrammatical. In contrast, if the positive ERP effect previously noted to syntactic anomalies in preschool children is modulated by lexical-semantic information, then that ERP effect should be different for jabberwocky sentences, possibly absent due to the lack of a need for sentence reanalysis, as noted by Canseco-Gonzalez (2000) and Münte et al. (1997). Thus, by examining how this syntactic ERP component behaves in jabberwocky sentences, we aimed to tease apart the relative roles of semantic and syntactic information in sentence processing at an early point in development at which grammatical development is well underway. We did not expect to observe a negativity resembling the LAN or ELAN to either type of sentence, given that those ERP effects were not noted in our previous studies with 30- to 48-month-old children (however, a LAN was reported for the 3-year-old children studied by Oberecker et al., 2005).

\section{METHODS}

\section{Participants}

Children were recruited from the Child Participant Pool at the University of Washington. All participants were healthy full-term 36-month-olds with monolingual English experience and with no known hearing deficits. Each child had no more than two mild ear infections before testing and was healthy and developing typically at the time of the study. Parents signed University of Washington ethics committee approved consent forms and were informed of the procedures and aims of the study. They received $\$ 15$ for their participation in the 1-hour session, and the children received a small toy. Parents were also asked to complete a vocabulary checklist composed of all the words used in the experiment; if a parent did not indicate that the child knew at least 95\% of the words on the list, the child's data were not included in the analyses.

Forty-seven children completed the experiment, but 31 children's recordings were not used due to insufficient numbers of artifact-free segments. Nineteen 36-month-old children (9 girls; mean age $=36.17$; $S D=$
0.38 ; range $=35.53-36.73$ ) were included in the analyses. Parents were asked about their own and their child's handedness. All children included in the analyses were right-handed and had no family history of left-handedness.

\section{Stimuli}

Forty regular transitive verbs, rated as being produced by $98 \%$ of 30-month-old children in the MacArthur-Bates Communicative Development Inventories (CDIs) lexical database (Dale \& Fenson, 1996), were used to build 80 regular past-tense sentences. Early acquired nouns, prepositions, pronouns, and determiners selected from the CDIs were also included in the sentences. All sentences were eight words in length and contained a prepositional phrase (e.g., My uncle watched a movie about my family). Half of the real sentences were correct, whereas the other half contained phrase structure violations. The phrase structure violations were created by reversing the word order of the preposition and preceding NP (e.g., *My uncle watched about a movie my family).

Eighty jabberwocky sentences were constructed using 40 pseudowords that were phonologically related to the content words (i.e., nouns, verbs) used in the real sentences. Pseudowords were created by extracting phoneme sequences from each content word, creating a matrix of different combinations, and selecting pseudowords that were phonotactically legal for English, as judged by two native English speakers who were students in Speech and Hearing Sciences. Pseudowords were controlled so that they matched the real English words in syllable number and final consonant (e.g., mool-ball) (see Appendix for list of stimulus sentences). All of the pseudoverbs were inflected as regular verbs (with the "ed" ending, e.g., watched-platched). Pilot behavioral testing was conducted with five native English-speaking adults in order to verify the syntactic violation point in the anomalous jabberwocky sentences. Subjects read the sentences and indicated the earliest point at which each sentence sounded grammatically incorrect. Based on this testing, 10 sentences were identified that had ambiguous violation points. These sentences were eliminated from the analyses. For the remaining jabberwocky sentences, the adults were in $100 \%$ agreement regarding the violation point.

All sentences were spoken by a female native English speaker. The sentences were recorded on a digital-audio system and sampled at $44 \mathrm{kHz}$ with a 16-bit resolution. The speaker rehearsed the sentences prior to recording to ensure that they sounded natural during the recording. The average sound pressure level of the sentences ranged from 63 to $67 \mathrm{~dB}$ SPL. In order to ensure precise time locking of the ERP to the onset of each critical word in the sentences, waveforms and spectrograms of the critical words were inspected. 
ERPs were time-locked to four different critical words. For real sentences, the ERP was time-locked to the onset of the preposition, which rendered the sentence: (a) syntactically anomalous (e.g., My uncle watched ABOUT a movie my family) or (b) nonanomalous (e.g., $M y$ uncle watched a movie ABOUT my family). For jabberwocky sentences, the ERP was time-locked to the onset of the last NP, which rendered the sentence: (c) syntactically anomalous (e.g., My macle platched about a flovie MY GARILY) or (d) nonanomalous (e.g., My macle platched a flovie about MY GARILY). The different locations of critical words across the real and jabberwocky sentences were necessary because, for the jabberwocky sentences, the violation would not be detected until the last NP was encountered.

The mean duration from the onset of nonanomalous real sentences to the critical word (i.e., preposition) was $1374.4 \mathrm{msec}(S D=161.84 \mathrm{msec})$. For real sentences with syntactic violations, the mean duration from the onset of the sentence to the preposition was $916.31 \mathrm{msec}$ $(S D=108.64 \mathrm{msec})$. For nonanomalous jabberwocky sentences, the mean duration from the onset of the sentence to the onset of the last NP was $1887.76 \mathrm{msec}$ $(S D=268.96 \mathrm{msec})$; for the jabberwocky sentences with syntactic violations, the mean duration from the onset of the sentence to the onset of the last NP was 1941.79 ( $S D=293.37 \mathrm{msec}$ ). Twenty additional sentences were included in each type of sentence condition (i.e., real and jabberwocky) as filler sentences.

\section{Procedure}

Each child was fitted with a 20-channel electrode cap (Electrocap International, Eaton, $\mathrm{OH}$ ) while playing with a research assistant. After conductive gel was applied to each electrode site, participants and experimenters moved into a sound-attenuated testing booth. Inside the booth, the impedances were measured and the child was seated in a comfortable chair close to his or her parent and approximately $1 \mathrm{~m}$ in front of a puppet theater. Participants listened passively to the stimuli while watching a live puppet show. The sentences were presented via loudspeakers mounted on the puppet theater, at interstimulus intervals of $1500 \mathrm{msec}$.

Each participant was tested in two sessions on the same day. Both experimental sessions lasted a total of approximately 1 hour, including the procedure of fitting the cap. In Session 1, 80 real sentences with and without syntactic violations were presented, and in Session 2, 80 jabberwocky sentences were presented. The order of the sessions was counterbalanced across participants.

\section{ERP Recording}

The electroencephalogram (EEG) was recorded from 20 tin electrodes secured in an elastic cap (Electrocap
International) at the following locations (according to the International 10-20 system): Fp1, Fp2, F3, F4, C3, C4, P3, P4, O1, O2, F7, F8, T3, T4, T5, T6, Fz, Cz, and Pz. The vertical electrooculogram (VEOG) was recorded from an infraorbital electrode placed on the infant's left cheek, in order to detect eye artifact in the EEG recordings. The recordings were referenced to the left mastoid; the brain electrical activity over the right mastoid was also recorded and did not reveal any condition-specific variations. Electrode impedances were kept below $10 \mathrm{k} \Omega$. The EEG signal was amplified with a gain of 20,000 by an Isolated Bioelectric Amplifier System Model SC-32/72BA (SA Instrumentation, San Diego, CA) with a bandpass of 0.1 to $100 \mathrm{~Hz}$, continuously sampled at $250 \mathrm{~Hz}$ by an analog-to-digital converter, and stored on a hard disk for further analysis.

\section{Data Analysis}

ERPs were computed off-line from 2048 msec epochs for each subject in each experimental condition. Epochs consisted of the $100 \mathrm{msec}$ preceding and $1948 \mathrm{msec}$ following the presentation of each individual critical word in each of the sentences. Automatic rejection of segments was carried out on the basis of the following criteria: Segments with electrical activity exceeding $\pm 150 \mu \mathrm{V}$ and amplifier blocking for more than $200 \mathrm{msec}$ at any electrode site were considered artifact and the entire segment was rejected. EEG segments from each subject were also visually inspected, and those segments with eye movements detected in the VEOG were rejected. Electrical activity from F7 minus F8 (used as the horizontal EOG criterion) that exceeded $\pm 50 \mu \mathrm{V}$ was also treated as artifact, and segments containing such artifact were rejected. Subjects with fewer than 18 artifact-free trials for each condition were excluded from the average. There were no significant differences in the percentages of trials eliminated due to artifact rejection across anomalous and nonanomalous real sentences $[M=33.8, S D=5.7$ and $M=34.1, S D=5.7$, respectively; $F(1,18)=0.049]$. Similarly, there were no significant differences in artifact rejection rates across anomalous and nonanomalous jabberwocky sentences $[M=36.2, S D=9.5$ and $M=$ $35.5, S D=9.8$, respectively; $F(1,18)=0.09$ ]. Further filtering was conducted using a band-pass of 0.5 to $30 \mathrm{~Hz}$. ERPs were re-referenced to the average right mastoid and left mastoid reference. Baseline correction was performed using the 100-msec prestimulus time window mentioned above.

A series of repeated-measures analyses of variance (ANOVAs) were performed on mean amplitude values for comparisons between syntactically anomalous and nonanomalous real and jabberwocky sentences. The Huynh-Feldt correction was applied to analyses with more than one degree of freedom in the numerator. Planned comparisons were reported as significant at the .05 level. 
Analyses proceeded in two stages. First, repeatedmeasures ANOVAs were performed separately for each sentence type (real and jabberwocky) on the ERP epoch 50-1600 msec in 50-msec consecutive intervals. Separate sets of repeated-measures ANOVAs were conducted for the data acquired at midline and lateral sites. For the midline sites, two-way repeated-measures ANOVAs were performed with violation (nonanomalous vs. anomalous sentences) and electrode site (Fz, Cz, and $\mathrm{Pz}$ ) as factors. For lateral sites, three-way repeated-measures ANOVAs were conducted with violation, hemisphere, and electrode site (Fp1-Fp2, F3-F4, C3-C4, P3-P4, O1-O2, F7-F8, T3-T4, T5-T6) as factors. For the midline sites, the analyses revealed two significant effects: main effect of condition on real sentences at 800-850 msec $[F(1,18)=5, p=.038]$ and main effect of condition on jabberwocky sentences at 1000-1050 msec $[F(1,18)=$ $8.2, p=.01]$. For the lateral sites, the analyses revealed two ranges of time for real sentences and two for jabberwocky sentences for which main effects and interactions were significant. Results for the comparison between syntactically anomalous and nonanomalous real and jabberwocky sentences are summarized in Table 1. For real sentences, one of the significant time windows extended from 500 to $750 \mathrm{msec}$ and the other one from 1050 to $1300 \mathrm{msec}$, reflecting a larger positive wave to the anomalous versus nonanomalous sentences. For jabberwocky sentences, the anomalous sentences elicited a significantly larger negativity than the nonanomalous sentences in two windows: 750-900 and 950-1150 msec. Based on these initial analyses, these longer time windows were used for the second stage of analysis. Repeated-measures ANOVAs were performed separately for each type of sentence (real and jabberwocky) in each time window. Again, separate analyses were conducted for the data acquired at midline and lateral sites.

\section{RESULTS}

\section{Real Sentences}

\section{0-750 msec Time Window}

Grand-average ERPs to the syntactically anomalous and nonanomalous real sentences at the onset of the target words are shown in Figure 1A. The anomalous sentences elicited a larger positivity than the nonanomalous sen-

Table 1. Results of the Comparison between Syntactically Anomalous and Nonanomalous Real and Jabberwocky Sentences

\begin{tabular}{|c|c|c|c|c|c|c|}
\hline \multirow{3}{*}{$\begin{array}{l}\text { Time Windows } \\
\text { (msec) }\end{array}$} & \multicolumn{6}{|c|}{$F$ Values } \\
\hline & \multicolumn{4}{|c|}{ Real Sentences } & \multicolumn{2}{|c|}{ Jabberwocky Sentences } \\
\hline & $V(1,18) d f$ & $V \times H(1,18) d f$ & $V \times E(a, b) d f$ & $V \times E \times H(a, b) d f$ & $V(1,18) d f$ & $V \times H(1,18) d f$ \\
\hline $500-550$ & & & & $(3.9,70.4)=2.5^{*}$ & & \\
\hline $550-600$ & & & & & & $5.9 *$ \\
\hline $600-650$ & & $4.8^{*}$ & & $(6.3,112.5)=2.2^{*}$ & & \\
\hline $650-700$ & & $6.3^{*}$ & & $(6.7,120.6)=2.2^{*}$ & & \\
\hline $700-750$ & & & & $(6.7,119.8)=2.3^{*}$ & & \\
\hline $750-800$ & & & & & & $7.1^{*}$ \\
\hline $800-850$ & $7.2 *$ & & & & & $5.9 *$ \\
\hline $850-900$ & & & & & & $5.5^{*}$ \\
\hline $900-1000$ & & & & & $5.1^{*}$ & \\
\hline $1000-1050$ & & & & & $10.8^{* *}$ & \\
\hline $1050-1100$ & & $7.1^{*}$ & & $(5.3,94.9)=2.4^{*}$ & $4.1^{*}$ & \\
\hline $1100-1150$ & & $10.9 * *$ & & $(5.6,101.1)=3^{*}$ & $4.1^{*}$ & \\
\hline $1150-1200$ & & & $(3.2,57)=2.9^{*}$ & & & \\
\hline $1200-1250$ & & & $(4.2,76.1)=4.3 * *$ & & & \\
\hline $1250-1300$ & & & $(2.7,48.2)=2.9^{*}$ & $(4.7,84.2)=2.8^{*}$ & & $4.9^{*}$ \\
\hline
\end{tabular}




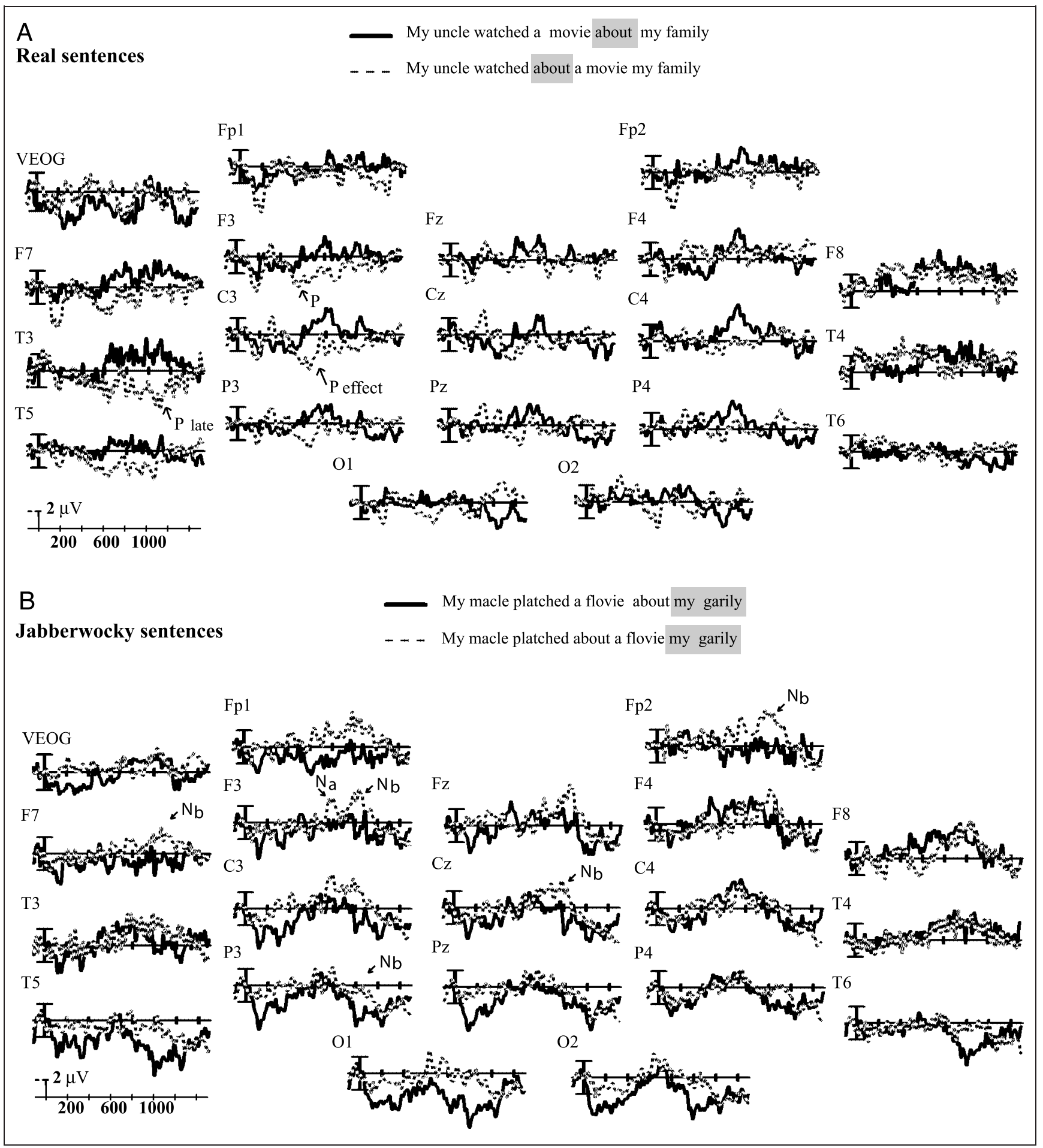

Figure 1. This figure shows grand-average ERPs to anomalous (dotted line) and nonanomalous (solid line): (A) real sentences at the onset of the preposition, and (B) jabberwocky sentences at the onset of the second noun phrase. Negative is plotted up. In (A), a larger amplitude positive response is observed for anomalous versus nonanomalous real sentences at left hemisphere sites (P600 and a later effect at T3 from 1050 to $1300 \mathrm{msec}$ ). In (B), larger amplitude negative responses are observed for the syntactically anomalous jabberwocky sentences $\left(\mathrm{N}_{\mathrm{a}}=\mathrm{N} 750-950\right.$ and $\left.\mathrm{N}_{\mathrm{b}}=\mathrm{N} 950-1150\right)$.

tences over the left hemisphere [Violation $\times$ Hemisphere $\times$ Electrode site interaction, lateral, $F(5.7$, $103.2)=2.5, p=.027]$. Planned comparisons between anomalous and nonanomalous sentences at each electrode site indicated that the larger positivity to anomalous sentences was significant only at three left hemisphere electrode sites: F3 $[F(1,18)=4.4, p=.05]$; T3 $[F(1,18)=7.1, p=.02]$; and $\mathrm{T} 5[F(1,18)=5.7, p=$ 
.03]. There were no effects of violation at any right hemisphere electrode sites.

\section{0-1300 msec Time Window}

A larger positivity was elicited by anomalous versus nonanomalous real sentences in this time window [Violation $\times$ Hemisphere $\times$ Electrode site interaction, lateral, $F(5.2,93.3)=2.6, p=.03$ ]. Planned comparisons between anomalous and nonanomalous sentences at each electrode site indicated that the larger positivity to anomalous sentences was significant only at T3 $[F(1,18)=8.9, p=.008]$.

\section{Jabberwocky Sentences}

\section{0-900 msec Time Window}

Grand-average ERPs to the syntactically anomalous and nonanomalous jabberwocky sentences at the onset of the last NP are shown in Figure 1B. A negative-going wave is observed to the jabberwocky sentences after the onset of the last NP. This negative wave is more prominent for the anomalous than the nonanomalous sentences over the left hemisphere [Violation $\times$ Hemisphere interaction, lateral, $F(1,18)=8.1, p=.011]$. Planned comparisons for violation made for each hemisphere showed that the differences were significant over the left but not the right hemisphere [Main effect of violation over the left hemisphere: $F(1,18)=5.3, p=.034]$.

\section{0-1150 msec Time Window}

A larger negativity was noted to the anomalous versus nonanomalous sentences [Violation main effect, lateral, $F(1,18)=7.8, p=.012]$. This effect was broadly distributed across the scalp; there were no main effects of hemisphere or interactions with hemisphere.

\section{DISCUSSION}

The present study examined auditory ERP responses in preschoolers to phrase structure violations occurring in real and jabberwocky sentences (i.e., sentences in which content words were replaced with pseudowords while grammatical functional words were retained). There were two important results. First, a larger positivity was elicited by the anomalous versus nonanomalous real sentences over left frontal, temporal, and posterior temporal sites, beginning at $500 \mathrm{msec}$ and ending at $750 \mathrm{msec}$, and followed by a second, later positive effect over the left temporal site. Second, two larger negativities were elicited by anomalous versus nonanomalous jabberwocky sentences, the first one with a left hemisphere distribution, beginning around $750 \mathrm{msec}$ after the onset of the critical word (the determiner or noun in the last NP), and lasting until $900 \mathrm{msec}$; the second one with a broad distribution from 950 to $1150 \mathrm{msec}$.

The positive effects noted to phrase structure violations in real sentences were generally consistent with those reported for children in previous studies, albeit with variations in latencies and scalp distributions, and may be interpreted as P600-type effects. The onset of this positivity was similar to that reported for phrase structure violations in the 32- to 38-month-old children studied by Harris (2001), although the scalp distribution of the effect was more left-lateralized in the present study. The results also showed similarities and differences when compared to those reported to phrase structure violations in 32-month-old children (Oberecker et al., 2005). In that study, phrase structure violations elicited an early positive effect with a right-central scalp distribution occurring prior to $300 \mathrm{msec}$, followed by a left-lateralized negative effect from approximately 300$700 \mathrm{msec}$, and a later positive effect with a right-central distribution occurring from 1100 to 1500 msec. Furthermore, the results were both similar to and different from those obtained in our previous studies of preschool-age children using morphosyntactic violations. The first positive effect (500-750 msec) observed in the present study occurred later, and was more left-lateralized, than the first positive effect (300-600 msec) to morphosyntactic violations found in 36- and 48-month-old children (Silva-Pereyra, Rivera-Gaxiola, et al., 2005). It was also more left-lateralized than the broadly distributed second positive effect (600-1000 msec) to morphosyntactic violations reported for 36- and 48-month-old children (Silva-Pereyra, Rivera-Gaxiola, et al., 2005).

The longer latencies of these positive effects in the present study could be due to the fact that the sentences might not have been considered "ungrammatical" until after the chosen onset point (the preposition). For example, the stem, "My uncle watched about ..." could be completed in a grammatically well-formed sentence: "My uncle watched about five football games on Sunday." Thus, the sentence structure, "My uncle watched about a movie my family" is temporarily ambiguous at the point that the preposition "about" is encountered. However, this was not the case in most of the sentences (see Appendix). Importantly, neither the phrase structure violations in real sentences in the present study nor the morphosyntactic violations in our previous studies elicited a negative effect resembling a LAN, in contrast to the results reported by Oberecker et al. (2005).

The negative effects elicited by phrase structure violations in jabberwocky sentences were also different from the negativities elicited by grammatical violations in other studies of young children. Both negative effects observed in the present study occurred at longer latencies than the bilateral negativity from 600 to $700 \mathrm{msec}$ elicited by phrase structure violations in jabberwocky 
sentences reported by Harris (2001). In addition, the negativities occurred at much longer latencies than the LAN-like effects to phrase structure violations in real sentences reported by Oberecker et al. (2005). The longer latency of the negative effects for jabberwocky sentences in the present study, compared to those reported by Harris, might have been due to how sentences were parsed by listeners. For example, in the sentence, "My macle platched about a flovie my garily," the phrase "a flovie my garily" could be parsed as the beginning of an object relative clause, as in "My uncle talked about a movie my family was in," in which case the listener would be expecting a verb in the relative clause after the pseudoword "garily" and would not consider the sentence ungrammatical until that point. In other cases, the pseudoverb could be interpreted as a verb embedded in a subject relative clause. For example, in "The bailgan plambed with the gree his jeg," the listener might parse this as the beginning of a construction analogous to "The mailman plagued with the flu his son gave him was in the hospital." In that case, the listener would be anticipating a verb right after the pseudoword "jeg." In both these cases, the sentences would be ambiguous until the very end, at the point when the listener is waiting for a verb and does not hear it. However, the alternate parsing of the anomalous jabberwocky sentences, in which the syntactic anomaly would be detected at the point of the final NP, is more probable, based on other literature showing that children this age tend to rely on canonical SVO interpretations rather than relative clause or other interpretations (Von Berger et al., 1996; Bates et al., 1984).

An alternative explanation for the late negativities observed for the processing of jabberwocky sentences could be that they are semantic rather than purely syntactic effects, reflecting children's attempts to make sense of the nonsensical sentences. One important fact that may explain the occurrence of negative rather than positive effects is the position of the ungrammatical point in the sentences used in the present study. In the present study, the violation occurred later in the sentence for the jabberwocky than for the real sentences, and this may have given listeners more time to construct possible sentence meanings. Osterhout (1997) has provided evidence that although sentenceembedded syntactically anomalous words elicit a P600like response in adults, sentence-final anomalous words can elicit an enhanced negative wave or an N400-like response. An interpretation of this sentence-final negativity is that it reflects the eventual semantic consequences of an ungrammatical (hence, not fully interpretable) sentence. Because the failed parse leads to problems at the semantic/conceptual level, the critical words elicit an enhanced N400 component. Furthermore, attempts at reanalysis might be less common when the anomaly is in sentence-final position than when it appears em- bedded within the sentence. Thus, the N400 amplitude may reflect the semantic anomaly engendered by an unparsable or misparsed sentence.

Notably, our results and those reported by Harris (2001), who used different types of jabberwocky stimuli with a different violation point, converge to show that a $\mathrm{P} 600$ is not elicited in ungrammatical sentences that have greatly reduced semantic content in children this age. These results are consistent with those observed in adults, as reported by Canseco-Gonzalez (2000) and Münte et al. (1997), although they differ from those reported by Hahne and Jescheniak (2001). Furthermore, our results show that a $\mathrm{P} 600$-like effect is observed in the same children when processing grammatical anomalies in real English sentences.

The results of the present study raise some interesting questions regarding levels of linguistic processing in young children. First, is there any evidence that the late negativities elicited in the jabberwocky condition reflect a purely syntactic effect rather than a semantic integration effect? Although it is not possible to answer this question only on the basis of our results and those reported by Harris (2001), the results provide some evidence that, in preschool children, semantic and syntactic processes interact during sentence processing, and syntactic structure is constructed taking semantic information into account. According to syntax-centered models, in which syntactic processing is believed to operate in the earliest stages of sentence processing, during jabberwocky sentence processing the parser should be able to build syntactic structure even when semantic information is distorted, as observed by Hahne and Jescheniak (2001) in their study of adults. Given that lexical entries cannot be activated by pseudowords, the integration would be completed solely on the basis of thematic role information and a P600-like positive effect would be observed, consistent with the P600 effects elicited by syntactic violations in real sentences. Neither our study nor the study conducted by Harris provides evidence for such an account. In contrast, according to interactive models, in which linguistic information from different levels is believed to interact from the beginning stages of sentence processing, the negative ERP effects elicited by jabberwocky sentences in our study could be interpreted as reflecting the use of multiple linguistic cues throughout the course of sentence processing in an effort to construct meaning. Young English learners, who have been exposed to a large proportion of SVO sentence structures in their input, may especially rely on what Ferreira (2003) has described as a basic "NVN/agent-patient" heuristic strategy, and employ a "shallow" form of sentence processing that does not take other syntactic information into account (see also Slobin, 1985). Thus, the negative effects elicited by syntactic violations in jabberwocky sentences most likely reflected attempts at semantic integration rather than the use of purely 
syntactic information, and may have reflected the interaction between the use of an NVN/agent-patient strategy, the limited semantic information present in the sentences, and whatever real-world pragmatic knowledge children this age were able to employ in the service of sentence interpretation.

A second interesting question raised by our results concerns the extent to which children this age are able to extract meaning from various linguistic cues. The amplitude of the $\mathrm{N} 400$ has been interpreted to reflect the "ease" with which a target can be integrated with the preceding context, at the semantic level (Osterhout \& Holcomb, 1995; Brown \& Hagoort 1993). However, the negative ERP effects noted in the present study may reflect the integration of linguistic information at a variety of levels (i.e., semantic, phonological, pragmatic, and syntactic levels). According to Hirsh-Pasek and Golinkoff (1996), children of preschool age can comprehend word order because there are redundant prosodic and semantic cues, although at this age they also focus their attention on syntactic cues to a larger extent than other possible sources of information. In our jabberwocky sentences, the main cues to sentence meaning were the regular past-tense inflections on pseudoverbs, the intact closed class words, and thematic role information. In addition, many of the pseudowords sounded sufficiently like real words, and may have been processed in a holistic way. Evidence from younger toddlers has suggested that, under processing situations that are high in their cognitive demands, fine phonetic detail is not always accessed in words (e.g., Mills et al., 2004; Pater, Stager, \& Werker, 2004; Stager \& Werker, 1997). Thus, it is possible that during this cognitively demanding sentence processing paradigm, children may have been using phonological information to map the pseudowords onto their representations of similar sounding real words. Although it might be argued that participants who heard the real sentences first would have attempted to map the jabberwocky sentences onto their memories of those previously heard real sentences, this is unlikely, given that the order of presentation of the sentence types (real vs. jabberwocky) was counterbalanced, and statistical analyses indicated no differences between the ERP effects observed in children who heard the real sentences first and those who heard the jabberwocky sentences first. It is more likely that children were using the limited lexical-semantic information present in the sentences to construct meaning. It has been shown that children can deduce the meanings of unknown verbs based on knowledge about other semantic and syntactic information in the sentence (Gleitman \& Gillette, 1999; Naigles, 1990, 1996; Naigles \& Hoff-Ginsberg, 1995; Fisher, 1994; Fisher, Gleitman, \& Gleitman, 1991; Landau \& Gleitman, 1985), as well as morphological markers on the verbs (e.g., Behrend, Harris, \& Cartwright, 1995). Our children might have generated expectations about what words should occur after the pseudoverb based on their interpretations of the pseudoverbs.

Finally, it is important to consider that the negativities noted to the syntactic anomalies in jabberwocky sentences may share some similarities with negative ERP effects reported in other language processing paradigms used with young children. Late negative effects have been reported in a variety of ERP studies with toddlers and preschoolers (Conboy \& Mills, 2006; Mills, Conboy, et al., 2005; Mills, Coffey-Corina, \& Neville, 1997). For example, a negative effect elicited to known versus unknown words from 600 to $900 \mathrm{msec}$ has been hypothesized to reflect the need for enhanced attention during word processing (Mills, Conboy, et al., 2005). Earlier negative effects to known versus unknown words linked to word meaning (e.g., from 200 to $400 \mathrm{msec}$ ) have also been reported in those studies, and a more focal distribution of those effects have been noted in children with higher language skills (see also Mills, Plunkett, Prat, \& Schafer, 2005; Mills, Coffey-Corina, \& Neville, 1993). Changes in both the morphology and topographical distributions of ERP components have also been noted from childhood to adulthood (Mills, Conboy, et al., 2005; Mills et al., 1997; Holcomb, Coffey, \& Neville, 1992). Many language-related ERP components, for example, are at first broadly distributed across the scalp. However, the meaning of ERP scalp asymmetries for language stimuli is a source of debate. Several ERP studies have shown left hemisphere asymmetries for language-related ERPs in infants (DehaeneLambertz, 2000; Molfese \& Molfese, 1979; Molfese, Freeman, \& Palermo, 1975), whereas others have shown broadly distributed effects that become left-lateralized with age and experience (Mills, Conboy, et al., 2005; Mills et al., 1997). For example, in an ERP study of 11-monthold infants, Thierry, Vihman, and Roberts (2003) found familiar-unfamiliar word effects in the same time range as Mills and colleagues (i.e., from approximately $250 \mathrm{msec}$ ), but these were larger over the right versus left hemisphere. Similarly, Conboy and Mills (2006) reported larger right hemisphere N200-400 effects to knownunknown words in the stronger language of bilingual 20-month-old children with larger vocabularies, and a more bilateral distribution in the weaker language of the same children and in both languages of children with smaller vocabularies. Thus, the meaning of the leftlateralized negative effect to syntactic anomalies in jabberwocky sentences in the present study is difficult to interpret. Studies of children at different ages and longitudinal studies would be useful for determining whether these left hemisphere scalp distributions change with age and/or language experience.

In conclusion, the appearance of a positive ERP effect to syntactic violations in real sentences that is similar to the P600 effect reported in other studies of children and adults indicates that the neural mechanisms of syntactic parsing are present during early language development, although the processes are slower in children than in 
adults. The results also suggest that semantics play a role in syntactic processing. Whereas syntactic violations in real English sentences elicited a positive ERP effect, syntactic violations in jabberwocky sentences, which contained reduced lexico-semantic information, elicited a left-distributed negative-going ERP effect, but not a positive effect. This negative effect appears to reflect the use of greater attentional resources and integration processes as listeners try to extract semantic information from the nonsense sentences, rather than the use of purely syntactic information. The results of this study with young children provide neurobiological evidence that favors interactive over modular theories of syntactic and semantic processing.

\section{APPENDIX}

\begin{tabular}{|c|c|c|}
\hline & Control Sentences & Jabberwocky Sentences \\
\hline \multirow[t]{2}{*}{1} & $\begin{array}{l}\text { The mailman climbed the } \\
\text { tree with his bag. }\end{array}$ & $\begin{array}{l}\text { The bailgan plambed the } \\
\text { gree with his jeg }\end{array}$ \\
\hline & $\begin{array}{l}\text { The mailman climbed with } \\
\text { the tree his bag. }\end{array}$ & $\begin{array}{l}\text { The bailgan plambed with } \\
\text { the gree his jeg }\end{array}$ \\
\hline \multirow[t]{2}{*}{2} & $\begin{array}{l}\text { My grandma kissed my } \\
\text { daddy on the cheek. }\end{array}$ & $\begin{array}{l}\text { My brondma gissed my } \\
\text { chidy on the preck }\end{array}$ \\
\hline & $\begin{array}{l}\text { My grandma kissed on } \\
\text { my daddy the cheek. }\end{array}$ & $\begin{array}{l}\text { My brondma gissed on my } \\
\text { chidy the preck }\end{array}$ \\
\hline \multirow[t]{2}{*}{3} & $\begin{array}{l}\text { The baby smashed the } \\
\text { table with her toy. }\end{array}$ & $\begin{array}{l}\text { The giby steshed the beable } \\
\text { with her tay }\end{array}$ \\
\hline & $\begin{array}{l}\text { The baby smashed with } \\
\text { the table her toy. }\end{array}$ & $\begin{array}{l}\text { The giby steshed with the } \\
\text { beable her tay }\end{array}$ \\
\hline \multirow[t]{2}{*}{4} & $\begin{array}{l}\text { My uncle watched a movie } \\
\text { about my family. }\end{array}$ & $\begin{array}{l}\text { My macle platched a flovie } \\
\text { about my garily }\end{array}$ \\
\hline & $\begin{array}{l}\text { My uncle watched about } \\
\text { a movie my family. }\end{array}$ & $\begin{array}{l}\text { My macle platched about } \\
\text { a flovie my garily }\end{array}$ \\
\hline \multirow[t]{2}{*}{5} & $\begin{array}{l}\text { My aunt watched television } \\
\text { in my bedroom. }\end{array}$ & $\begin{array}{l}\text { My dant platched selegosion } \\
\text { in my lodram }\end{array}$ \\
\hline & $\begin{array}{l}\text { My aunt watched in } \\
\text { television my bedroom. }\end{array}$ & $\begin{array}{l}\text { My dant platched in } \\
\text { selegosion my lodram }\end{array}$ \\
\hline \multirow[t]{2}{*}{6} & $\begin{array}{l}\text { The nurse poured some } \\
\text { water into the pitcher. }\end{array}$ & $\begin{array}{l}\text { The berse dured some } \\
\text { gluter into the betcher }\end{array}$ \\
\hline & $\begin{array}{l}\text { The nurse poured into } \\
\text { some water the pitcher. }\end{array}$ & $\begin{array}{l}\text { The berse dured into some } \\
\text { gluter the betcher }\end{array}$ \\
\hline \multirow[t]{2}{*}{7} & $\begin{array}{l}\text { My dolly touched the cat } \\
\text { with her hand. }\end{array}$ & $\begin{array}{l}\text { My cholly daunched the glat } \\
\text { with her shond }\end{array}$ \\
\hline & $\begin{array}{l}\text { My dolly touched with } \\
\text { the cat her hand. }\end{array}$ & $\begin{array}{l}\text { My cholly daunched with the } \\
\text { glat her shond }\end{array}$ \\
\hline \multirow[t]{2}{*}{8} & $\begin{array}{l}\text { The boys loved the stories } \\
\text { about Christmas. }\end{array}$ & $\begin{array}{l}\text { The broys juved the chories } \\
\text { about grastmas }\end{array}$ \\
\hline & $\begin{array}{l}\text { The boys loved about } \\
\text { the stories Christmas. }\end{array}$ & $\begin{array}{l}\text { The broys juved about the } \\
\text { chories grastmas }\end{array}$ \\
\hline
\end{tabular}

APPENDIX (continued)

\section{Control Sentences}

9 My friend wanted his pancake with jelly.

My friend wanted with his pancake jelly.

10 That girl loved the stories about the country.

That girl loved about the stories the country.

11 My babysitter played peek-a-boo at home.

My babysitter played at peek-a-boo home.

12 My brother wanted his teddybear on the bed.

My brother wanted on his teddybear the bed.

13 My teacher shared her yogurt with my brother.

My teacher shared with her yogurt my brother.

14 My mommy wiped her face with a napkin.

My mommy wiped with her face a napkin.

15 My uncle closed the door with his hand.

My uncle closed with the door his hand.

16 My sister dressed her doll on the table.

My sister dressed on her doll the table.

17 That man bumped my truck with his foot.

That man bumped with my truck his foot.

18 The nurse liked the movies about animals.

The nurse liked about the movies animals.

19 My teacher played the song about Santa Claus.

My teacher played about the song Santa Claus.

20 My sister opened the present from my uncle.
Jabberwocky Sentences

My biend clonted his brongake with grally

My biend clonted with his brongake grally

That borl juved the chories about the sontry

That borl juved about the chories the sontry

My gibyfiter chayed beek-a-lu at chome

My gibyfiter chayed at beek-a-lu chome

My cother clonted his gaddyler on the lod

My cother clonted on his gaddyler the lod

My bacher clored her pregurt with my cother

My bacher clored with her pregurt my cother

My bammy juped her nace with a garkin

My bammy juped with her nace a garkin

My macle clised the chor with his shond

My macle clised with the chor his shond

My bacter grissed her choll on the beable

My bacter grissed on her choll the beable

That gan lomped my morck with his tet

That gan lomped with my morck his tet

The berse huked the flovies about polimals

The berse huked about the flovies polimals

My bacher chayed the teng about Danta Praus

My bacher chayed about the teng Danta Praus

My bacter drepened the chosent from my macle 
APPENDIX (continued)

\section{Control Sentences}

My sister opened from the present my uncle.

21 The monkey touched the bananas in that tree.

The monkey touched in the bananas that tree.

22 My babysitter covered the toys with my hat.

My babysitter covered with the toys my hat.

23 The child wanted a pancake from that store.

The child wanted from a pancake that store.

24 My grandma baked a muffin in the oven.

My grandma baked in a muffin the oven.

25 My mommy kissed my daddy in the kitchen

My mommy kissed in my daddy the kitchen.

26 My daddy wiped his hands with a napkin.

My daddy wiped with his hands a napkin

27 The doctor checked my body with his camera.

The doctor checked with my body his camera.

28 My teacher tasted the ice cream at the school.

My teacher tasted at the ice cream the school.

29 The clown splashed my face with water.

The clown splashed with my face water.

30 My aunt spilled some juice on my bed.

My aunt spilled on some juice my bed.

31 The man dumped the garbage in the trash.

The man dumped in the garbage the trash.
Jabberwocky Sentences

My bacter drepened from the chosent my macle

The nurkey daunched the buranas in that gree

The nurkey daunched in the buranas that gree

My gibyfiter huvered the tays with my trit

My gibyfiter huvered with the tays my trit

The frild clonted a brongake from that spere

The frild clonted from a brongake that spere

My brondma leked a taffin in the baven

My brondma leked in a taffin the baven

My bammy gissed my chiddy in the skachen

My bammy gissed in my chiddy the skachen

My chiddy juped his shonds with a garkin

My chiddy juped with his shonds a garkin

The brotor gicked daby with his pamera

The brotor gicked with daby his pamera

My bacher splated the bice glem at the skal

My bacher splated at the bice glem the skal

The bawn chashed my nace with gluter

The bawn chashed with my nace gluter

My dant plalled some birce on my lod

My dant plalled on some birce my lod

The gan dremped the birbage in the presh

The gan dremped the birbage in the presh
APPENDIX (continued)

\begin{tabular}{|c|c|c|}
\hline & Control Sentences & Jabberwocky Sentences \\
\hline \multirow[t]{2}{*}{32} & $\begin{array}{l}\text { The policeman chased } \\
\text { the zebra in the zoo. }\end{array}$ & $\begin{array}{l}\text { The brolicegan cosed the } \\
\text { pabra in the foo }\end{array}$ \\
\hline & $\begin{array}{l}\text { The policeman chased } \\
\text { in the zebra the zoo. }\end{array}$ & $\begin{array}{l}\text { The brolicegan cosed in } \\
\text { the pabra the foo }\end{array}$ \\
\hline \multirow[t]{2}{*}{33} & $\begin{array}{l}\text { The boys carried their } \\
\text { books inside their bags. }\end{array}$ & $\begin{array}{c}\text { The broys dorried their } \\
\text { gaks inside their jegs }\end{array}$ \\
\hline & $\begin{array}{l}\text { The boys carried inside } \\
\text { their books their bags. }\end{array}$ & $\begin{array}{l}\text { The broys dorried inside } \\
\text { their gaks their jegs }\end{array}$ \\
\hline \multirow[t]{2}{*}{34} & $\begin{array}{l}\text { The baby bumped the } \\
\text { bench with my book. }\end{array}$ & $\begin{array}{l}\text { The giby dremped the } \\
\text { sanch with my gak }\end{array}$ \\
\hline & $\begin{array}{l}\text { The baby bumped with } \\
\text { the bench my book. }\end{array}$ & $\begin{array}{l}\text { The giby dremped with } \\
\text { the sanch my gak }\end{array}$ \\
\hline \multirow[t]{2}{*}{35} & $\begin{array}{l}\text { My sister closed the book } \\
\text { at the school. }\end{array}$ & $\begin{array}{l}\text { My bacter clised the gak } \\
\text { at the skal }\end{array}$ \\
\hline & $\begin{array}{l}\text { My sister closed at the } \\
\text { book the school. }\end{array}$ & $\begin{array}{l}\text { My bacter clised at the } \\
\text { gak the skal }\end{array}$ \\
\hline \multirow[t]{2}{*}{36} & $\begin{array}{l}\text { My aunt hugged my bear } \\
\text { with her arms. }\end{array}$ & $\begin{array}{l}\text { My dant cleagged my ler } \\
\text { with her berms }\end{array}$ \\
\hline & $\begin{array}{l}\text { My aunt hugged with } \\
\text { my bear her arms. }\end{array}$ & $\begin{array}{l}\text { My dant cleagged with } \\
\text { my ler her berms }\end{array}$ \\
\hline \multirow[t]{2}{*}{37} & $\begin{array}{l}\text { The cowboy loved his } \\
\text { bread with butter. }\end{array}$ & $\begin{array}{l}\text { The bawbroy juved his } \\
\text { cread with satter }\end{array}$ \\
\hline & $\begin{array}{l}\text { The cowboy loved with } \\
\text { his bread butter. }\end{array}$ & $\begin{array}{l}\text { The bawbroy juved with } \\
\text { his cread satter }\end{array}$ \\
\hline \multirow[t]{2}{*}{38} & $\begin{array}{l}\text { The nurse knocked my } \\
\text { knees with the hammer. }\end{array}$ & $\begin{array}{l}\text { The berse chacked my } \\
\text { clees with the treemer }\end{array}$ \\
\hline & $\begin{array}{l}\text { The nurse knocked with } \\
\text { my knees the hammer. }\end{array}$ & $\begin{array}{c}\text { The berse chacked with } \\
\text { my clees the treemer }\end{array}$ \\
\hline \multirow[t]{2}{*}{39} & $\begin{array}{l}\text { The man fixed my tricycle } \\
\text { with glue. }\end{array}$ & $\begin{array}{l}\text { The gan daxed my brafycle } \\
\text { with clo }\end{array}$ \\
\hline & $\begin{array}{l}\text { The man fixed with my } \\
\text { tricycle glue. }\end{array}$ & $\begin{array}{l}\text { The gan daxed with my } \\
\text { brafycle clo }\end{array}$ \\
\hline \multirow[t]{2}{*}{40} & $\begin{array}{l}\text { My brother kicked the } \\
\text { ball in the garden. }\end{array}$ & $\begin{array}{l}\text { My cother fincked the } \\
\text { mool in the farden }\end{array}$ \\
\hline & $\begin{array}{l}\text { My brother kicked in } \\
\text { the ball the garden. }\end{array}$ & $\begin{array}{l}\text { My cother fincked in the } \\
\text { mool the farden }\end{array}$ \\
\hline
\end{tabular}

\section{Acknowledgments}

This work was supported by NIH Research Core Grant, University of Washington P30 DC04661. This work was also supported by grants to P. K. K. from NIH (HD37954), and the University of Washington's Institute for Learning and Brain Sciences. We thank Denise Padden, Kathryn Schoolcraft, and Robin Cabaniss for technical support, and Nitya Sethuraman for her comments on an earlier version of the manuscript. We are especially indebted to the children and their parents who participated in these studies, without whom the research would not be possible. 
Reprint requests should be sent to Juan Silva-Pereyra, Institute for Learning and Brain Sciences, University of Washington, Box 357988, Seattle, WA 98195-7988, or via e-mail: jsilvapereyra@ yahoo.com.

\section{Note}

1. These early negativities have not been observed in all studies of morphosyntactic violations in adults (see Kim \& Osterhout, 2005). However, this may be at least partly due to the presentation rate of words (Friederici, 1995).

\section{REFERENCES}

Bates, E., Devescovi, A., \& Wulfeck, B. (2001). Psycholinguistics: A cross-language perspective. Annual Review of Psychology, 52, 369-398.

Bates, E., \& Goodman, J. (1999). On the emergence of grammar from lexicon. In B. MacWhinney (Ed.), The emergence of language (pp. 29-80). Mahwah, NJ: Erlbaum.

Bates, E., \& MacWhinney, B. (1989). Functionalism and the competition model. In B. MacWhinney \& E. Bates (Eds.), The crosslinguistic study of sentence processing (pp. 3-76). New York: Cambridge University Press.

Bates, E., MacWhinney, B., Caselli, C., Devescovi, A., Natale, F., \& Venza, V. (1984). A cross-linguistic study of the development of sentence interpretation strategies. Child Development, 55, 341-354.

Behrend, D. A., Harris, L. L., \& Cartwright, K. B. (1995). Morphological cues to verb meaning: Verb inflections and the initial mapping of verb meanings. Journal of Child Language, 22, 89-106.

Brown, C. M., \& Hagoort, P. (1993). The processing nature of the N400: Evidence from masked priming. Journal of Cognitive Neuroscience, 5, 34-44.

Brown, R. (1973). A first language. Cambridge: Harvard University Press.

Canseco-Gonzalez, E. (2000). Using the recording of event-related brain potentials in the study of sentence processing. In Y. Grodzinsky, L. Shapiro, \& D. Swinney (Eds.), Language and the brain: Representation and processing (pp. 229-266). San Diego, CA: Academic Press.

Chomsky, N. (1981). Lectures on government and binding. Dordrecht: Foris.

Clahsen, H., \& Fesler, C. (2006). Grammatical processing in language learners. Applied Psycholinguistics, 27, 3-42.

Conboy, B. T., \& Mills, D. (2006). Two languages, one developing brain: Effects of vocabulary size on bilingual toddlers' event-related potentials to auditory words. Developmental Science, 9, F1-F12.

Coulson, S., King, J. W., \& Kutas, M. (1998). Expect the unexpected: Event-related brain response to morphosyntactic violations. Language and Cognitive Processes, 13, 21-58.

Dale, P. S., \& Fenson, L. (1996). Lexical development norms for young children. Behavior Research Methods, Instruments, and Computers, 28, 125-127.

Dehaene-Lambertz, G. (2000). Cerebral specialization for speech and non-speech stimuli in infants. Journal of Cognitive Neuroscience, 12, 449-460.

Devescovi, A., D’Amico, S., Smith, S., Mimica, I., \& Bates, E. (1998). The development of sentence comprehension in Italian and Serbo-Croatian: Local versus distributed cues. In D. Hillert (Ed.), Syntax and semantics: Vol. 31.
Sentence processing: A cross-linguistic perspective (pp. 345-377). San Diego, CA: Academic Press.

Dick, F., Wulfeck, B., Krupa-Kwiatkowski, M., \& Bates, E. (2004). The development of complex sentence interpretation in typically developing children compared with children with specific language impairments or early unilateral focal lesions. Developmental Science, 7, 360-377.

Elman, J., Bates, E., Johnson, M., Karmiloff-Smith, A., Parisi, D., \& Plunkett, K. (1996). Rethinking innateness: A connectionist perspective on development. Cambridge: MIT Press.

Elman, J. L., Hare, M., \& McRae, K. (2005). Cues, constraints, and competition in sentence processing. In M. Tomasello \& D. I. Slobin (Eds.), Beyond nature-nurture: Essays in honor of Elizabeth Bates (pp. 111-138). Mahwah, NJ: Erlbaum.

Ferreira, F. (2003). The misinterpretation of noncanonical sentences. Cognitive Psychology, 47, 164-203.

Fisher, C. (1994). Structure and meaning in the verb lexicon: Input for a syntax-aided verb learning procedure. Language and Cognitive Processes, 9, 473-517.

Fisher, C., Gleitman, H., \& Gleitman, L. R. (1991). On the semantic content of subcategorization frames. Cognitive Psychology, 23, 331-392.

Frazier, L. (1987). Sentence processing: A tutorial review. In M. Coltheart (Ed.), Attention and performance XII (pp. 559-585). London: Erlbaum.

Frazier, L. (1995). Constraint satisfaction as a theory of sentence processing. Journal of Psycholinguistic Research, 24, 437-468.

Frazier, L. (1998). Getting there (slowly). Journal of Psycholinguistic Research, 27, 123-146.

Friederici, A. D. (1995). The time course of syntactic activation during language processing: A model based on neuropsychological and neurophysiological data. Brain and Language, 50, 259-281.

Friederici, A. D. (2002). Towards a neural basis of auditory sentence processing. Trends in Cognitive Sciences, 6, 78-84.

Friederici, A. D. (2005). Neurophysiological markers of early language acquisition: From syllables to sentences. Trends in Cognitive Sciences, 9, 481-488.

Friederici, A. D., Hahne, A., \& Mecklinger, A. (1996). Temporal structure of syntactic parsing: Early and late event-related brain potential effects elicited by syntactic anomalies. Journal of Experimental Psychology: Learning, Memory, and Cognition, 22, 1219-1248.

Friederici, A. D., Hahne, A., \& Saddy, D. (2002). Distinct neurophysiological patterns reflecting aspects of syntactic complexity and syntactic repair. Journal of Psycholinguistic Research, 31, 45-63.

Friederici, A. D., \& Kotz, S. A. (2003). The brain basis of syntactic processes: Functional imaging and lesion studies. Neuroimage, 20(Suppl. 1), S8-S17.

Friederici, A. D., Pfeifer, E., \& Hanhe, A. (1993). Event-related brain potentials during natural speech processing: Effects of semantic, morphological and syntactic violations. Brain Research, 1, 183-192.

Gleitman, L. R., \& Gillette, J. (1999). The role of syntax in verb learning. In W. C. Ritchie \& T. K. Bhatia (Eds.), Handbook of child language acquisition (pp. 279-295). San Diego: Academic Press.

Goldberg, A. E., Casenhiser, D. M., \& Sethuraman, N. (2004). Learning argument structure generalizations. Cognitive Linguistics, 15, 289-316.

Gunter, T. C., Friederici, A. D., \& Schriefers, H. (2000). Syntactic gender and semantic expectancy: ERPs reveal 
early autonomy and late interaction. Journal of Cognitive Neuroscience, 12, 556-568.

Hagoort, P., Brown, C. M., \& Groothusen, J. (1993). The syntactic positive shift (SPS) as an ERP measure of syntactic processing. Language and Cognitive Processes, 8, 439-483.

Hagoort, P., Brown, C. M., \& Osterhout, L. (1999). The neurocognition of syntactic processing. In C. M. Brown \& P. Hagoort (Eds.), The neurocognition of language (pp. 273-316). New York: Oxford University Press.

Hahne, A., Eckstein, K., \& Friederici, A. D. (2004). Brain signatures of syntactic and semantic processes during children's language development. Journal of Cognitive Neuroscience, 6, 1302-1318.

Hahne, A., \& Jescheniak, J. D. (2001). What's left if the jabberwocky gets the semantics? An ERP investigation into semantic and syntactic processes during auditory sentence comprehension. Cognitive Brain Research, 11, 199-212.

Harris, A. M. (2001). Processing semantic and grammatical information in auditory sentences: Electrophysiological evidence from children and adults (Dissertation abstract). Dissertation Abstracts International: Section B. The Sciences and Engineering, 61, 6729.

Hirsh-Pasek, K., \& Golinkoff, R. M. (1996). A coalition model of language comprehension. In K. Hirsh-Pasek \& R. M. Golinkoff (Eds.), The origins of grammar: Evidence from early language comprehension (pp. 150-203). Cambridge: MIT Press.

Holcomb, P. J., Coffey, S. A., \& Neville, H. J. (1992). Visual and auditory sentence processing: A developmental analysis using event-related brain potentials. Developmental Neuropsychology, 8, 203-241.

Kail, M., \& Charvillat, A. (1988). Local and topological processing in sentence comprehension by French and Spanish. Journal of Child Language, 15, 637-662.

Kim, A., \& Osterhout, L. (2005). The independence of combinatory semantic processing: Evidence from event-related potentials. Journal of Memory and Language, 52, 205-222.

Kuhl, P. (2004). Early language acquisition. Nature Reviews Neuroscience, 5, 831-843.

Kutas, M., \& Federmeier, K. (2000). Electrophysiology reveals semantic memory use in language comprehension. Trends in Cognitive Sciences, 4, 463-470.

Kutas, M., \& Hillyard, S. A. (1980). Reading senseless sentences: Brain potentials reflect semantic incongruity. Science, 207, 203-205.

Kutas, M., \& Hillyard, S. A. (1983). Event-related brain potentials to grammatical errors and semantic anomalies. Memory \& Cognition, 11, 539-550.

Kutas, M., \& Van Petten, C. (1994). Psycholinguistics electrified: Event-related brain potential investigations. In M. A. Gernsbacher (Ed.), Handbook of psycholinguistics (pp. 83-143). San Diego, CA: Academic Press.

Kutas, M., Van Petten, C., \& Kluender, R. (2006). Psycholinguistics electrified II:1995-2005. In M. Traxler \& M. A. Gernsbacher (Eds.), Handbook of psycholinguistics (2nd ed, pp. 659-724). New York: Elsevier Press.

Landau, B., \& Gleitman, L. (1985). Language and experience: Evidence from the blind child. Cambridge, MA: Harvard University Press.

Lieven, E., Behrens, H., Speares, J., \& Tomasello, M. (2003). Early syntactic creativity: A usage-based approach. Journal of Child Language, 30, 333-370.

Lieven, E., Pine, J. M., \& Baldwin, G. (1997). Lexically-based learning and early grammatical development. Journal of Child Language, 24, 187-219.
Lindner, K. (2003). The development of sentenceinterpretation strategies in monolingual German-learning children with and without specific language impairment. Linguistics, 41, 213-254.

MacDonald, M. C., Pearlmutter, N. J., \& Seidenberg, M. S. (1994). The lexical nature of syntactic ambiguity resolution. Psychology Review, 101, 676-703.

MacWhinney, B. (1999) (Ed.) Emergence of language. Mahwah, NJ: Lawrence Erlbaum Associates.

MacWhinney, B., \& Bates, E. (1989). Cross-linguistic study of sentence processing. New York: Cambridge University Press.

MacWhinney, B., Bates, E., \& Kliegl, R. (1984). Cue validity and sentence interpretation in English, Italian and German. Journal of Verbal Learning and Verbal Behavior, 23, 127-150.

Marslen-Wilson, W., \& Tyler, L. K. (1980). The temporal structure of spoken language understanding. Cognition, 8, $1-71$.

Mills, D., Coffey-Corina, S., \& Neville, H. (1993). Language acquisition and cerebral specialization in 20-month-old infants. Journal of Cognitive Neuroscience, 5, 317-334.

Mills, D., Coffey-Corina, S. A., \& Neville, H. (1997). Language comprehension and cerebral specialization from 13-20 months [Special issue on origins of language disorders]. In D. Thal \& J. Reilly (Eds.), Developmental Neuropsychology, 13, 397-446.

Mills, D., Conboy, B. T., \& Paton, C. (2005). How learning new words shapes the organization of the infant brain. In L. Namy (Ed.), Symbol use and symbolic representation (pp. 123-153). Mahwah, NJ: Erlbaum.

Mills, D. L., Plunkett, K., Prat, C., \& Schafer, G. (2005). Watching the infant brain learn words: Effects of language and experience. Cognitive Development, 20, 19-31.

Mills, D., Prat, C., Zangl, R., Stager, C. L., Neville, H., \& Werker, J. (2004). Language experience and the organization of brain activity to phonetically similar words: ERP evidence from 14- and 20-month-olds. Journal of Cognitive Neuroscience, 16, 1452-1464.

Molfese, D. L., Freeman, R. B., \& Palermo, D. S. (1975). The ontogeny of brain lateralization for speech and nonspeech stimuli. Brain and Language, 2, 356-368.

Molfese, D. L., \& Molfese, V. J. (1979). Hemisphere and stimulus differences as reflected in the cortical responses of newborn infants to speech stimuli. Developmental Psychology, 15, 505-511.

Morris, J., \& Holcomb, P. J. (2005). Event-related potentials to violations of inflectional verb morphology in English. Brain Research, Cognitive Brain Research, 25, 963-981.

Münte, T. F., \& Heinze, H. J. (1994). ERP negativities during syntactic processing of written words. In H. J. Heinze, T. F. Munte, \& G. R. Mangun (Eds.), Cognitive electrophysiology (pp. 211-238). Boston: Birkhauser.

Münte, T. F., Matzke, M., \& Johannes, S. (1997). Brain activity associated with syntactic incongruencies in words and pseudo-words. Journal of Cognitive Neuroscience, 9, 318-329.

Naigles, L. (1990). Children use syntax to learn verb meanings. Journal of Child Language, 17, 357-374.

Naigles, L. (1996). The use of multiple frames in verb learning via syntactic bootstrapping. Cognition, 58, 221-251.

Naigles, L. R., \& Hoff-Ginsberg, E. (1995). Input to verb learning: Evidence for the plausibility of syntactic bootstrapping. Developmental Psychology, 31, 827-837. 
Oberecker, R., \& Friederici, A. D. (2006). Syntactic event-related potential components in 24-month-olds' sentence comprehension. NeuroReport, 17, 1017-1021.

Oberecker, R., Friedrich, M., \& Friederici, A. D. (2005). Neural correlates of syntactic processing in two-year-olds. Journal of Cognitive Neuroscience, 17, 1667-1678.

Osterhout, L. (1997). On the brain response to syntactic anomalies: Manipulations of word position and word class reveal individual differences. Brain and Language, 59, 494-522.

Osterhout, L., \& Holcomb, P. (1995). Event-related potentials and language comprehension. In M. D. Rugg \& M. G. H. Coles (Eds.), Electrophysiology of mind: Event-related brain potentials and cognition (pp. 171-215). New York: Oxford University Press.

Osterhout, L., McLaughlin, J., \& Bersick, M. (1997). Event-related brain potentials and human language. Trends in Cognitive Sciences, 1, 203-209.

Pater, J., Stager, C., \& Werker, J. F. (2004). The perceptual acquisition of phonological contrasts. Language, 80 , 361-379.

Pinker, S. (1994). The language instinct: How the mind creates language. New York: HarperCollins.

Pinker, S. (1999). Words and rules: The ingredients of language. New York: Basic Books.

Pinker, S., \& Ullman, M. T. (2002). The past and future of the past tense. Trends in Cognitive Sciences, 6, 456-463.

Reyes, I., \& Hernández, A. E. (2006). Sentence interpretation strategies in emergent bilingual children and adults. Bilingualism, 9, 51-69.

Savage, C., Lieven, E., Theakston, A., \& Tomasello, M. (2003). Testing the abstractness of children's linguistic representations: Lexical and structural priming of syntactic constructions in young children. Developmental Science, 6, 557-567.

Silva-Pereyra, J., Klarman, L., Lin, L. J. F., \& Kuhl, P. K. (2005). Sentence processing in 30-month-old children:
An event-related brain potential study. NeuroReport, 16, 645-648.

Silva-Pereyra, J., Rivera-Gaxiola, M., \& Kuhl, P. (2005). An event-related brain potential study of sentence comprehension in preschoolers: Semantic and morphosyntactic processing. Cognitive Brain Research, 23, 247-258.

Slobin, D. I. (1985). Crosslinguistic evidence for the language-making capacity. In D. Slobin (Ed.), The crosslinguistic study of language acquisition: Vol. 2. Theoretical issues (pp. 1157-1249). Hillsdale, NJ: Erlbaum.

Stager, C. L., \& Werker, J. F. (1997). Infants listen for more phonetic detail in speech perception than in word-learning tasks. Nature, 388, 381-382.

Thierry, G., Vihman, M., \& Roberts, M. (2003). Familiar words capture the attention of 11-month-olds in less than $250 \mathrm{~ms}$. NeuroReport, 14, 2307-2310.

Tomasello, M. (2000). First steps toward a usage-based theory of language acquisition. Cognitive Linguistics, 11, 61-82.

Tomasello, M. (2003). Constructing a language: A usage-based theory of language acquisition. Cambridge: Harvard University Press.

Thal, D., \& Flores, M. (2001). Development of sentence interpretation strategies by typically developing and late-talking toddlers. Journal of Child Language, 28, $173-179$.

Ullman, M. T. (2004). Contributions of memory circuits to language: The declarative/procedural model. Cognition, 92, 231-270.

Von Berger, E., Wulfeck, B., Bates, E., \& Fink, N. (1996). Developmental changes in real-time sentence processing. First Language, 16, 193-222.

Wiig, E. H., Secord, W., \& Semel, E. M. (1992). Clinical evaluation of language fundamentals-Preschool. San Antonio, TX: The Psychological Corporation. 